\title{
Evaluation of an Early Childhood Caries Preventive Program Stretching from Pregnancy, in Areas with Low Socioeconomic Status in Sweden: 12-Month Results
}

\section{Caroline Blomma ${ }^{1}$, Kerstin Aronsson ${ }^{2}$, Mats Bågesund ${ }^{3,4}$, Elin Karlsson ${ }^{3}$, Madeleine Borgstedt Risberg ${ }^{2}$, Lotta Ranggård ${ }^{3}$, Elisabeth Wärnberg Gerdin ${ }^{5,6}$, and Thomas Davidson ${ }^{7, *}$}

${ }^{1}$ Östergötland Public Dental Service, Region Östergötland, Linköping, Sweden

${ }^{2}$ Center for Organizational Support and Development, Region Östergötland, Linköping University, Linköping, Sweden

${ }^{3}$ Centre for Orthodontics and Pediatric Dentistry, Östergötland Public Dental Service, Region Östergötland, Linköping, Sweden

${ }^{4}$ Division of Pediatrics, Department of Clinical and Experimental Medicine, Linköping University, Linköping, Sweden

${ }^{5}$ Dental Research Department, Public Dental Service, Region Örebro County, Örebro, Sweden

${ }^{6}$ School of Health and Medical Sciences, Örebro University, Örebro, Sweden

${ }^{7}$ Center for Medical Technology Assessment, Department of Medical and Health Sciences, Linköping University, Linköping, Sweden

*Corresponding author: Thomas Davidson, Center for Medical Technology Assessment, Department of Medical and Health Sciences, Linköping University, Linköping, Sweden, Tel: +46709200344; E-mail: THOMAS.DAVIDSON@LIU.SE

Received: 07 Dec, 2019 | Accepted: 18 Dec, 2019 | Published: 24 Dec, 2019

Citation: Blomma C, Aronsson K, Bågesund M, Karlsson E, Risberg MB, et al. (2019) Evaluation of an Early Childhood Caries Preventive Program Stretching from Pregnancy, in Areas with Low Socioeconomic Status in Sweden: 12-Month Results. Int J Dent Oral Health 6(1): dx.doi.org/10.16966/2378-7090.311

Copyright: (C) 2019 Blomma C, et al. This is an open-access article distributed under the terms of the Creative Commons Attribution License, which permits unrestricted use, distribution, and reproduction in any medium, provided the original author and source are credited.

\begin{abstract}
The purpose of this prospective controlled intervention study was to evaluate an Early Childhood Caries (ECC) prevention program from pregnancy to 12 months of age. Pregnant women living in socioeconomically disadvantaged areas in Sweden received an individual interdisciplinary ECC prevention program consisting of oral health promoting talks using motivational interviewing technique. Findings show a tendency towards a decrease in the proportion of children with high risk of ECC in the intervention group, although non- significant. The program reached a higher proportion of mothers, whose children had increased risk of ECC, with an oral health message during pregnancy compared to ordinary routines.
\end{abstract}

Keywords: Caries; Children; Promotion; Inequality; Interdisciplinary

List of Abbreviations: ECC: Early Childhood Caries; SES: Socioeconomic Status; MI: Motivational Interviewing; PDS: Public Dental Services; MHS: Maternal Healthcare Services; CHS: Child Healthcare Services

\section{Introduction}

Dental health is unequally distributed globally and nationally. Early childhood caries (ECC) is more common among children living in areas with low Socioeconomic Status (SES) than among children in areas with higher SES [1-3]. The same pattern has been found in Region Östergötland in Sweden, where also an increasing difference in ECC prevalence between areas with low and high SES recently has been found [4,5]. ECC is however at large preventable and previous studies have shown that early prevention and parental education in oral health behaviors provide the best conditions for improvement in children's oral health [6-8]. It is increasingly recommended that children visit the dental service during the first year of life for caries risk assessment and preventive interventions if necessary $[9,10]$. Previous studies have also shown that the earlier the preventive program is initiated, the better are the chances of avoiding ECC $[11,12]$. It has been suggested that screening of pregnant women from low-SES areas may be helpful in early identification of children with increased risk of ECC $[11,12]$ and that interdisciplinary co-operation in prevention of ECC can be successful [9,13-15]. However, families living in areas with low SES may participate to a lesser extent in caries prevention programs [16]. In order to reduce differences in oral health, extended efforts should be directed in proportion to the needs of the population, so called universal proportionalism [17].

In 2013, the oral health prospective intervention study 'Equal oral health in children' was initiated in a low-SES area within Region Östergötland, Sweden. It was a directed at pregnant women in a highrisk population based on Region Östergötland's work on mapping and analyzing caries in children in relation to the region's socioeconomic 
distribution [5]. The overall objective was to create and evaluate a model for interdisciplinary health promotion and ECC prevention among families living in areas with a high prevalence of ECC and low SES and to reduce socioeconomic related differences in caries prevalence in children. The specific aim of the study was to reduce caries prevalence in an area with low SES. Vital for the relevance of the model was to reach the families with increased risk of ECC in their children, a group scientifically recognized as hard to reach. The model consisted of a preventive program starting during pregnancy with ECC risk assessment. The program was based on a health promotion family perspective, and included oral health promoting talks with Motivational Interviewing (MI) as a method. The study comprised an interdisciplinary cooperation between the Public Dental Services (PDS), Maternal Healthcare Services (MHS), and Child Healthcare Services (CHS) and intended to continue until the expected child was three years old.

The purpose of the present evaluation was to study participation in the program, the mothers' demographic characteristics, self-perceived oral health, and oral health behaviors, and the children's ECC risk assessment from pregnancy to 12 months of age.

\section{Material and Methods}

\section{Ethical approval}

Ethical approval was received from the Regional Ethical Review
Board in Linköping before the start of the project (refs: 2012/259-31, 2018/367-32).

The time schedule for the study is presented in figure 1.

\section{Study groups}

The intervention group was recruited consecutively from January 1, 2013 to December 31, 2014 using the following inclusion criteria: pregnant woman visiting the MHS for the first time in their current pregnancy and living in one of two low-SES areas in a city in Southeast of Sweden. SES was defined as the proportion of high-income individuals living in each very small area of the municipality of the specified the city [5].

In the most disadvantaged areas the prevalence of ECC was about 55 percent [5]. According to a power calculation (significance level of 0.05 ) based on an expected 15 percentage units decrease of ECC prevalence a sample size of 173 mothers was required in the intervention group. Recruitment was planned to last until 175 mothers agreed to attend, but for at least one year.

The control group consisted of pregnant women who visited the MHS during the study period for the first time in their current pregnancy and who lived in the specified city but not in the areas chosen for the intervention group. Hence, the SES of the control group is expected to be higher and used to study whether the project succeeded to include

\begin{tabular}{|c|c|c|}
\hline $\begin{array}{l}\text { Time } \\
\text { line }\end{array}$ & $\begin{array}{r}\text { STUD } \\
\text { All pregnant wo } \\
\text { in a city in Southeast of Sw }\end{array}$ & $\begin{array}{l}\text { OUPS } \\
\text { visiting MHS } \\
\text { n during } 2013 \text { and } 2014\end{array}$ \\
\hline \multirow{3}{*}{ 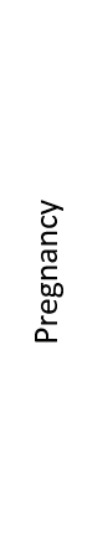 } & $\begin{array}{c}\text { INTERVENTION GROUP } \\
\text { Pregnant women in specified low SES } \\
\text { areas in the city } \\
\mathrm{n}=175\end{array}$ & \begin{tabular}{|c} 
CONTROL GROUP \\
All pregnant women (intervention \\
group excluded) during study period \\
$n=1325$
\end{tabular} \\
\hline & $\begin{array}{c}\text { First visit to MHS: } \\
\text { Questionnaire (A) for ECC risk } \\
\text { assessment } \\
\text { Appointment for an oral health } \\
\text { promoting talk }\end{array}$ & $\begin{array}{c}\text { First visit to MHS: } \\
\text { Questionnaire(A) for ECC risk } \\
\text { assessment }\end{array}$ \\
\hline & $\begin{array}{c}\text { One or more oral health promoting } \\
\text { talks at the PDS, according to } \\
\text { assessed ECC risk }\end{array}$ & $\begin{array}{l}\text { Ordinary } \\
\text { routines in MHS }\end{array}$ \\
\hline 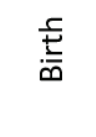 & $\begin{array}{c}\text { Individual ECC prevention program at } \\
\text { the PDS, according to assessed ECC } \\
\text { risk }\end{array}$ & $\begin{array}{c}\text { Ordinary } \\
\text { routines in dental care and CHS }\end{array}$ \\
\hline 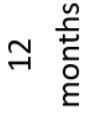 & $\begin{array}{l}\text { Oral health promoting talk } \\
\text { Questionnaire (B) by postal mail }\end{array}$ & Questionnaire (B) by postal mail \\
\hline & linary routines & $\begin{array}{l}\text { MHS = Maternal healthcare services } \\
\text { PDS = Public dental services }\end{array}$ \\
\hline & nts in oral health project & $\begin{array}{l}\mathrm{CHS}=\text { Child health services } \\
\mathrm{ECC}=\text { Early childhood caries }\end{array}$ \\
\hline
\end{tabular}

Figure 1: Time schedule for the study. 
and affect the group that was aimed for. The children in the control group were born during the same period of time as the children in the intervention group. They underwent ordinary routines in maternal and dental care and did not receive the additional ECC preventive program that was given to the intervention group.

When the pregnant mothers were invited to their first MHS visit, they were to receive information about the program and give their written consent to participate in the study.

Relevant subgroups will be studied separately in each study group.

\section{Questionnaire}

A questionnaire was developed for studying demographic characteristics, oral health behaviors, self-perceived oral health and assessment of risk for ECC. The questionnaire was designed in consultation with psychologists and health-educated communicators with cultural knowledge and was translated into the ten most common languages in the neighborhood. The questions were based on well-known risk factors for ECC regarding the mothers social conditions, self-perceived oral health, and oral health behaviors $[11,12,18]$. The child's ECC risk was graded $0=$ low risk, $1=$ risk, and $2=$ high risk.

Mothers in both study groups answered the questionnaire during pregnancy (A) and when the child was 12 months old (B).

The answers were also used to follow up changes in the families concerning ECC risk and oral health behaviors pre-birth and at 12 months.

\section{ECC prevention program based on ECC risk assessment}

The mothers in the intervention group received an ECC prevention program which began during pregnancy. Depending on the assessed ECC risk, the mother and child were offered oral health controls for the child and supportive oral health promoting talks at the PDS. The program also included practical instructions about ECC prevention and how the oral health promoting talks were to be performed.

\section{Oral health promoting talks using motivational interviewing}

Mothers in the intervention group were offered regular oral health promoting talks using the MI technique. Moderators who worked as dental hygienists or dental assistants conducted the talks at the PDS. The moderators underwent the same MI education and were professionally trained in the MI technique by psychologist. Interpreters were used when needed.

\section{Interdisciplinary co-operation}

The MHS, CHS, and PDS all have a mission of influencing lifestyle and living habits such as diet, hygiene and exercise among their visitors/patients. A systematic collaboration between these three services was developed to enable the implementation of the program.

All pregnant women were invited to participate in the program at their first visit to the MHS. Women in the intervention group were invited to the PDS for participation in the ECC preventive program. When the child was born, the cooperation with PDS was transferred to the CHS.

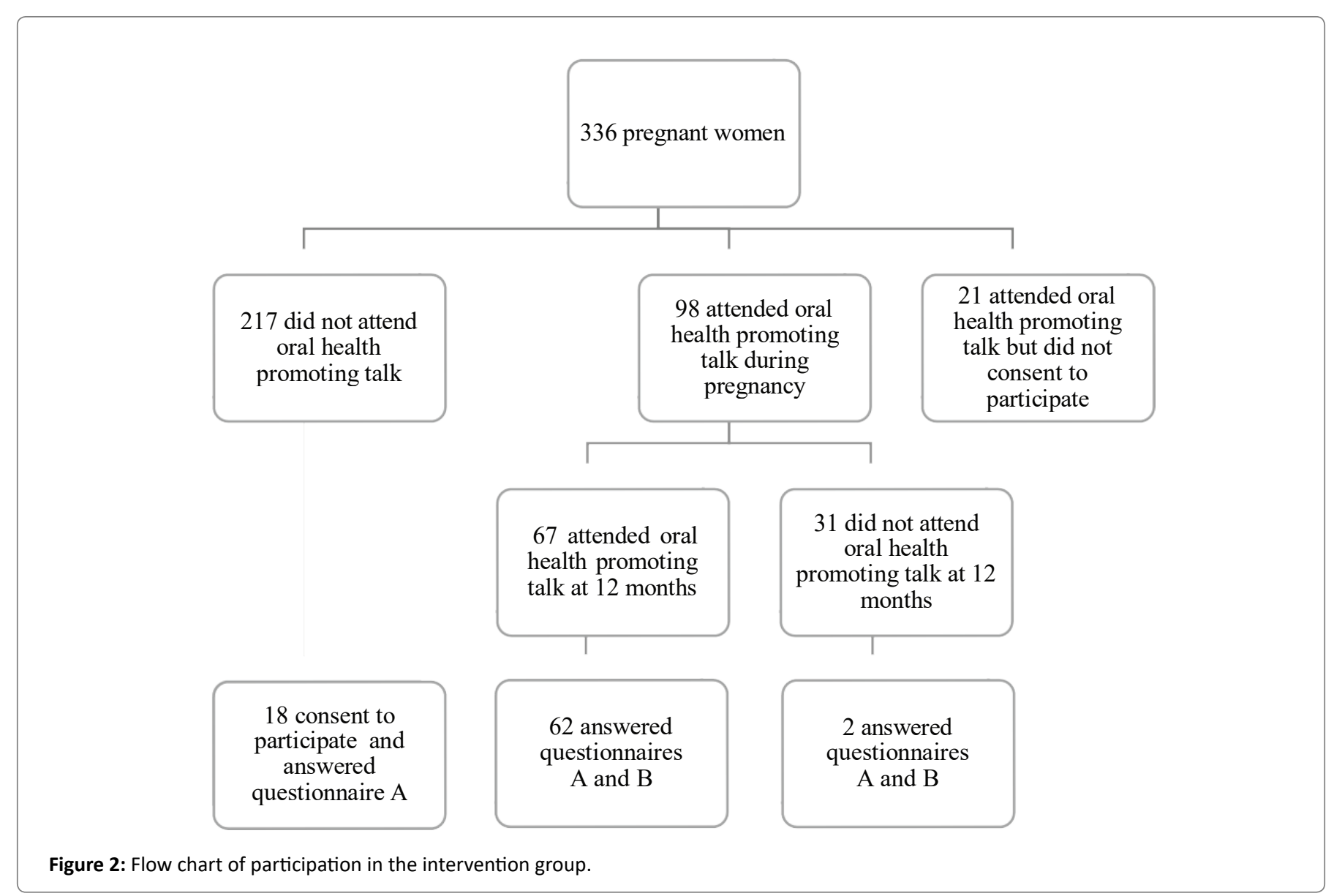


Table 1: Demographics characteristics.

\begin{tabular}{|c|c|c|c|c|c|}
\hline Demographic factor & $\begin{array}{l}\text { Intervention group } \\
\qquad n=64\end{array}$ & $\begin{array}{c}\text { Control group (I) } \\
\qquad n=426\end{array}$ & P-value (I) & $\begin{array}{c}\text { Intervention group non- } \\
\text { participating (II) } \\
n=18\end{array}$ & P-value (II) \\
\hline College education & $31.3 \%$ & $70.7 \%$ & $<0.001$ & $0 \%$ & 0.01 \\
\hline Born in Sweden & $11.1 \%$ & $85.2 \%$ & $<0.001$ & $22.2 \%$ & 0.22 \\
\hline Has a job & $17.2 \%$ & $89.4 \%$ & $<0.001$ & $27.8 \%$ & 0.32 \\
\hline Living with the other parent & $79.0 \%$ & $96.7 \%$ & $<0.001$ & $76.5 \%$ & 0.82 \\
\hline
\end{tabular}

Demographic characteristics of mothers in the intervention group who participated in the program compared to (I) the control group, and (II) mothers in the intervention group who did not participate in the program.

Table 2: Differences between intervention and control group in questionnaire a (pregnancy) and B (12 months after child birth).

\begin{tabular}{|c|c|c|c|c|c|c|}
\hline \multirow[b]{2}{*}{ Variable } & \multicolumn{3}{|c|}{ Questionnaire A } & \multicolumn{3}{|c|}{ Questionnaire B } \\
\hline & $\begin{array}{l}\text { Intervention group } \\
\qquad \mathrm{n}=64\end{array}$ & Control group $n=426$ & P-value & $\begin{array}{l}\text { Intervention group } \\
\qquad n=64\end{array}$ & $\begin{array}{c}\text { Control group } \\
n=426\end{array}$ & P-value \\
\hline Satisfied with dental health & $56.5 \%$ & $90.4 \%$ & $<0.001$ & $61.3 \%$ & $86.6 \%$ & $<0.001$ \\
\hline $\begin{array}{l}\text { Visits dental care regularly for } \\
\text { examination of the teeth }\end{array}$ & $39.3 \%$ & $84.2 \%$ & $<0.001$ & $54.1 \%$ & $81.8 \%$ & $<0.001$ \\
\hline Brushes teeth in the morning & $88.9 \%$ & $96.7 \%$ & 0.004 & $92.1 \%$ & $95.5 \%$ & 0.237 \\
\hline Brushes teeth in the evening & $88.9 \%$ & $96.5 \%$ & 0.007 & $96.8 \%$ & $95.5 \%$ & 0.639 \\
\hline Uses toothpaste & $95.8 \%$ & $99.8 \%$ & $<0.001$ & $100 \%$ & $99.8 \%$ & 0.726 \\
\hline
\end{tabular}

\section{Statistical Methods}

A z-test was used to examine differences in proportions between the intervention group and the control group responses to the questionnaires, and the McNemar test was used to determine whether the answers differed between the two questionnaires. P-values $<0.05$ were considered statistically significant.

\section{Results}

\section{Participation in the program}

The expected number of participants in the intervention group had not been reached after one year, why the recruitment period was extended to two years. After two years, 336 pregnant mothers had been invited to the intervention group; 119 of them accepted the offer and participated in at least one oral health promoting talk during pregnancy. Ninety-eight of them consented to participate in the research study, which means that the participation during pregnancy was $29 \%$. Of these, $32 \%$ discontinued participation after the first oral health promoting talk, providing a total number of 67 participants completing the program. The remaining 217 did not attend any oral health promoting talk during their pregnancy. It was not considered feasible to continue the inclusion of new participants in the intervention group after two years. Figure 2 describes the participation and dropout for the different parts of the program in the intervention group. The two women who responded to questionnaire A and B but had not attended to the oral health promoting talk at 12 months had been at the PDS for individual supportive actions after birth.

\section{Non-response analysis}

Of the 217 women who were invited to the intervention group but did not participate in the program, 94 declined participation either directly to the MHS or later in contact with the PDS, 30 did not attend their appointments or could not be reached when the PDS tried to contact them, and for 92 there was no registered reason for not participating in the program. However, for one case language problems was stated by the PDS as the reason for not participating.
Eighteen of these 217 women had completed the first questionnaire, consented to participate in the study, and could be compared to the women who participated (Table 1). The group that did not participate had a lower proportion $(\mathrm{p}=0.01)$ of women with college education, a higher proportion $(\mathrm{p}=0.22)$ born in Sweden, and a higher proportion $(\mathrm{p}=0.32)$ with a job.

\section{Demographic characteristics}

In the intervention group 64 mothers responded to both questionnaires (A and B). Of the 2630 mothers in the control group, 426 answered both questionnaires. There were significant differences between the intervention group and the control group regarding several demographic variables, as shown in table 1.

The average age of mothers at childbirth was 29 years in the intervention group and 31 years in the control group (range: 17-43 years and $19-45$ years, respectively).

The group of immigrants in the control group differed from the group of immigrants in the intervention group in that a larger proportion of the immigrants (68\%) in the control group had a college education compared to the intervention group (34\%). Of the mothers with college education in the control group, $81 \%$ had a job when the child was 12 months old, while only $5 \%$ of the immigrant mothers with college education in the intervention group had a job by that time.

\section{Oral health and oral health behavior}

As can be seen in table 2, the intervention group had worse values than the control group for all the analyzed variables concerning oral health and oral health behavior in questionnaire A. By the time questionnaire B was administered, the differences between the two groups had evened out and become non-significant for three variables but remained significant for two. When comparing the results from questionnaire A and B within each group no significant change for any of the analyzed variables was found; although, for example, the proportion of mothers visiting dental care regularly had increased by fifteen percentage units in the intervention group. 
On the question whether they felt healthy or not, most of the mothers in both groups responded that they did, both during pregnancy and when the child was one year old.

\section{ECC risk assessment}

ECC risk assessments using the answers to questionnaires A and B are presented in figure 3 for both groups.

In the intervention group, during pregnancy $11 \%$ of the children were considered to be at high risk (score $=2)$ of developing ECC. When the children were at the age of 12 months, this proportion had decreased by eight percentage units to $3,2 \%(\mathrm{p}=0.125)$.

In the control group a large proportion was estimated to have a low risk (score $=0$ ) of developing ECC, both when assessed during pregnancy and when assessed at 12 months. The small proportion with risk of developing ECC (score=1-2) had increased $(\mathrm{p}=0.019)$ from $13 \%$ to $17 \%$.

\section{Discussion}

In this study we evaluated the 12 -month results of a very early ECC prevention program (due to continue to 36 months) aimed at a high risk ECC population in an area with low socioeconomic status in Sweden. Participation in the program, demographic characteristics, perceived oral health, oral health behaviors, and ECC risk assessments after 12 months were studied.

\section{Participation in the program}

In ordinary routines in the MHS all expecting mothers, regardless of SES were invited to receive group information about oral health, but the participation rate was low: $4 \%$ in 2013 and $2 \%$ in 2014. Since families living with low SES have a lower frequency of visits and a larger dropout rate from dental visits for their children it is expected that the participation for this group is even lower in this initiative $[19,20]$. The present program reached a higher proportion of pregnant women in low SES (29 percent) in comparison to this ordinary routine.
The difficulties in including participants is in line with previous knowledge about the targeted group $[19,20]$. It is also possible that not all prospective participants received an invitation.

Language barriers as well as cultural differences may have been aggravating factors in the recruitment process and can be assumed to have contributed to the low participation rate in the intervention group. This is despite the fact that the material in the program was translated into different languages, interpreters were used when needed, and the program was designed in consultation with healtheducated communicators with cultural knowledge. The extensive program information (required for ethical reasons) could have contributed to the loss of participants in the program and in fewer consenting to participate in the research study. Another reason for difficulties in recruitment might be that the offer of participation could have been perceived as stigmatizing for residents in the intervention area, which may have led some potential participants to abstain.

Due to shortcomings in the recruitment process, the collection of data for the study took longer than planned, and the calculated sample size was not reached despite prolonging the recruitment from one to two years. Further extension of the recruitment time was discussed but was not considered feasible, firstly because the control group was already large and secondly because of difficulties in motivating the MHS personnel to continue the recruitment process.

Since there were major difficulties in recruiting mothers to the intervention group, it is appropriate to ask whether the disciplines involved in this study are the right ones for recruiting and cooperating in an interdisciplinary oral health program of this kind, from the perspective of both the prospective participants (the mothers) and the personnel. Three disciplines-MHS, CHS, and PDS-were involved in the program since they all have a public health assignment, oral health included. However, there may be differences in how this public health assignment is interpreted in terms of oral health. Sheiham A, Watt RG [21] emphasized the need to work in interdisciplinary partnership, with the underlying and mutual risk factors of chronic diseases

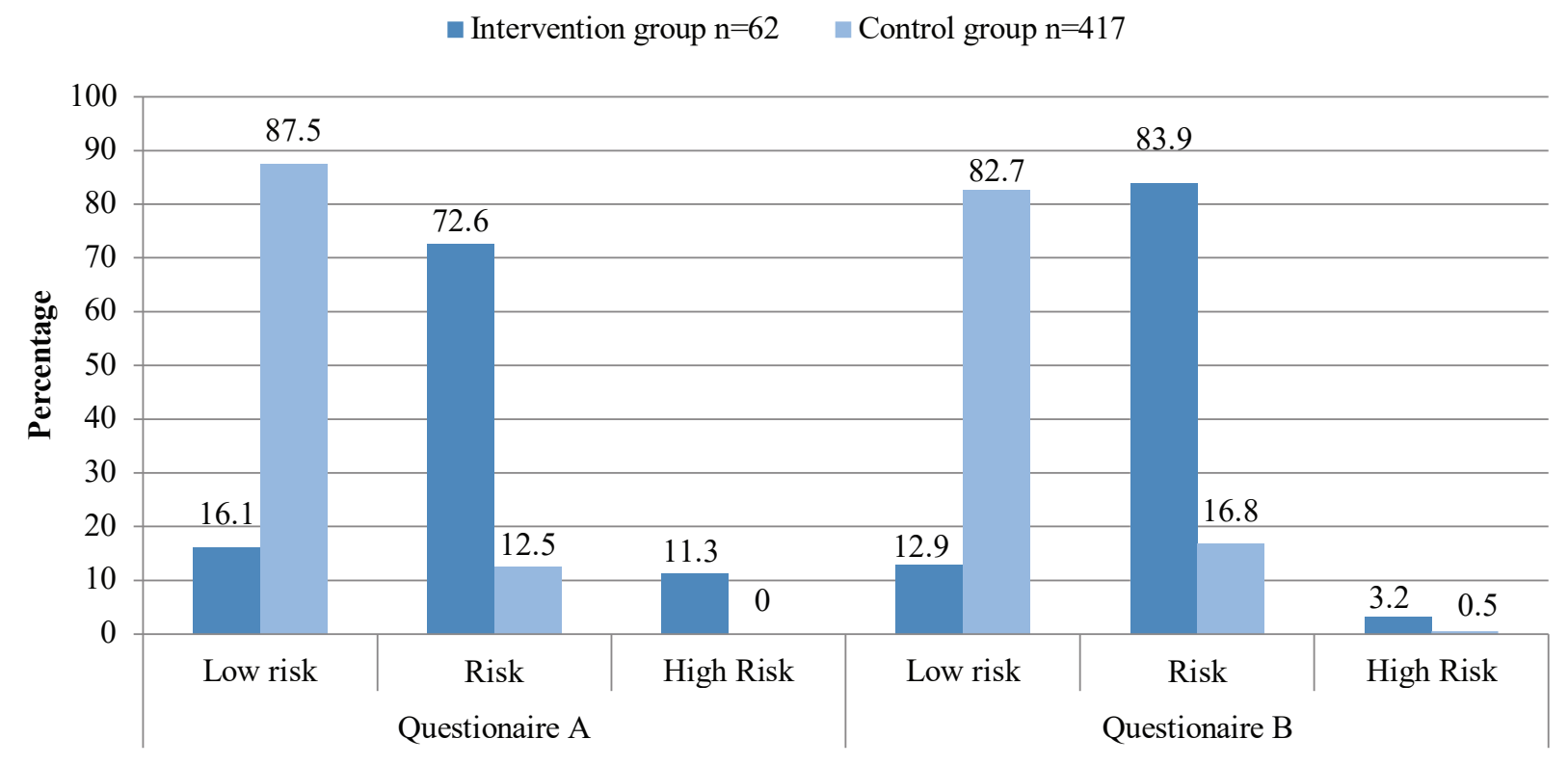

Figure 3: Percentage distribution of ECC risk during pregnancy (questionnaire A) and at 12 months (questionnaire B). 
and recent research has proven this to be efficient in terms of caries prevention [22,23]. By integrating oral health into the educational level for all professions working with public health, oral health issues can be addressed by all disciplines when applicable, resulting in betterquality care and better public health in general.

In addition to the large drop-out rate in the recruitment phase, $32 \%$ discontinued participation during the ongoing program. There were probably several reasons for this, but one might have been that the mothers were not enough motivated or did not consider themselves to have the time. Another reason might have been the perceptions of the selected method for communicating, motivational interviewing, which may have been perceived as unaccustomed by the personnel, the mothers, and the interpreters who participated in the oral health promoting talks when needed.

\section{Demographics}

Previous research has reported that demographic factors, including the parents' educational level, income, immigrant and occupational background are indicators of ECC risk in children $[1,24,25]$. Analyses of the demographics of the study groups showed that, in comparison to the control group, a significantly larger proportion of mothers in the intervention group lived under these circumstances, associated with a higher risk of ECC in their children. This indicates that the intervention, which was targeted at a high-risk population, reached the families that it was intended to reach; that is, those with an increased risk of developing ECC.

The questionnaire was designed to identify circumstances affecting families' risk of ECC development in their children. We found that the questionnaire identified a higher proportion of children with increased risk of ECC in areas that previous studies has pointed out as low SES areas with an increased risk of ECC. This indicates that the questionnaire might be a useful tool for early screening for ECC and a validation of the questionnaire will be performed henceforth.

Splieth $\mathrm{CH}$, et al. [16] addressed the problem with non-responders to caries prevention and the fact that they more often might be the once with increased risk of caries. In present study the demographic differences between the mothers in the intervention group who chose to participate in the program and those who did not indicated that the group who did not participate had a larger proportion of mothers who were born in Sweden and had a job. It is possible that these circumstances led prospective participants to believe that the program was not about them or aimed at them. Having a job may also have prevented mothers from having the time or opportunity to attend the program. These tendencies of demographic differences may indicate that the program did not recruit only the most well-established mothers in the areas with low SES but the also the ones with increased risk of ECC, although no major conclusions can be drawn due to the low number of mothers in the sample.

\section{Oral health and oral health behaviors}

Among the mothers in the intervention group, no major change in oral behaviors appeared between pregnancy and when the child was 12 months, but tendencies of improvement were seen in terms of regularity in dental care visits and in perceived dental health. In the control group the trends tended to be reversed. As the number of mothers participating in the program was far lower than the number required achieving statistical significance, we cannot expect to see more than trends in our results. In addition, a German study, including 706 children in the intervention group, evaluated an early interdisciplinary preventive program for ECC starting during pregnancy [23]. At the age of four the children in the test group differed significantly from them in the control group terms of oral health behaviors in favor of the test group.

Another study [26] directed at a high risk population of parents to preschool children, reported improvement of self-reported behaviors for their children after participating in several interactive theorybased behavioral classes. The method chosen for changing parental oral behavior in this study, MI, has shown variable results in recent research. Colvara BC, et al. [27] concluded it to be more effective than conventional oral health education in reducing caries prevalence in children. Batliner TS, et al. [28] and Henshaw MM, et al. [29] reported MI was effective in improving maternal knowledge but had no effect on oral health behaviors or ECC progression. Further evaluation of this intervention in terms of caries prevalence is to be performed.

\section{ECC risk assessment}

In the intervention group, the proportion of children considered at low risk of developing ECC remained unchanged from pregnancy to 12 months of age, but the proportion at high risk decreased. The tendency in the control group was in the opposite direction. The improvement, in reduced ECC risk, support the notion demonstrated in earlier studies, that parental education should be addressed in oral health interventions for young children [30-32].

\section{Conclusions}

The design of this program allowed a higher proportion of expecting mothers to be reached with an oral health message during pregnancy than had previously been achieved by offering group information at the MHC. Furthermore, the intervention reached the families who were targeted; that is, those with increased risk of ECC. The questionnaire seems to be a useful tool for early ECC screening. We found trends of improved oral health behaviors and decrease in ECC risk in the intervention group.

\section{Declarations}

\section{Ethics approval and consent to participate}

Subjects have given their written informed consent. The study received ethical approval from the Regional Ethical Review Board in Linköping (refs: 2012/259-31, 2018/367-32).

\section{Consent for Publication}

Not applicable.

\section{Availability of Data and Materials}

The datasets used and/or analyzed during the current study are available from the corresponding author on reasonable request.

\section{Author's Contributions}

LR, EWG and KA initiated the project. All authors participated in the data analysis and writing the manuscript. MBR made the statistical analysis. $\mathrm{CB}$ and TD finalized the manuscript. All authors approved the final version.

\section{Acknowledgements}

We thank Östergötland Public Dental Service, Region Östergötland, and all our cooperating partners in performing this program, for the possibility of making this study.

\section{Conflicts of Interests and Sources of Funding}

The authors have no conflict of interest to declare. The authors 
are alone responsible for the content and writing of the paper. Östergötland Public Dental Service financed this project but had no influence on the study.

\section{References}

1. Kramer AA, Petzold M, Hakeberg M, Ostberg A (2018) Multiple Socioeconomic Factors and Dental Caries in Swedish Children and Adolescents. Caries Res 52: 42-50.

2. Baggio S, Abarca M, Bodenmann P, Gehri M, Madrid C (2015) Early childhood caries in Switzerland: a marker of social inequalities. BMC Oral Health 15: 82.

3. Lambert MJ, Vanobbergen JSN, Martens LC, De Visschere LMJ (2017) Socioeconomic inequalities in caries experience, care level and dental attendance in primary school children in Belgium: a cross-sectional survey. BMJ Open 7: e015042.

4. Aronsson K, Johansson A, Holmberg S (2016) Socioekonomi och tandhälsa hos barn och ungdomar i Östergötland 2015.

5. Aronsson K, Mako E, Walter L (2011) Socioeconomi and oral health in children and adolescents in Östergötland 2009.

6. Kramer AA, Skeie MS, Skaare AB, Espelid I, Ostberg A (2014) Caries increment in primary teeth from 3 to 6 years of age: a longitudinal study in Swedish children. Eur Arch Paediatr Dent 15: 167-173.

7. De Castilho ARF, Mialhe FL, de Souza Barbosa T, Puppin-Rontani RM (2013) Influence of family environment on children's oral health: a systematic review. J Pediatr (Rio J) 89: 116-123.

8. Twetman S, Dhar V (2015) Evidence of Effectiveness of Current Therapies to Prevent and Treat Early Childhood. Caries Pediatr Dent 37: 246-253.

9. Garcia R, Borrelli B, Dhar V, Douglass J, Gomez FR, et al (2015) Progress in Early Childhood Caries and Opportunities in Research, Policy, and Clinical Management. Pediatr Dent 37: 294-299.

10. Plutzer K, Keirse MJNC (2014) Influence of an Intervention to Prevent Early Childhood Caries Initiated before Birth on Children's Use of Dental Services up to 7 Years of Age. Open Dent J 8: 104-108.

11. Feldens CA, Kramer PF, Sequeira MC, Rodrigues PH, Vitolo MR (2012) Maternal education is an independent determinant of cariogenic feeding practices in the first year of life. Eur Arch Paediatr Dent 13: 70-75.

12. Leong PM, Gussy MG, Barrow SL, de Silva-Sanigorski A, Waters E (2013) A systematic review of risk factors during first year of life for early childhood caries. Int J Paediatr Dent 23: 235-250.

13. Douglass JM, Clark MB (2015) Integrating Oral Health Into Overall Health Care to Prevent Early Childhood Caries: Need, Evidence, and Solutions. Pediatr Dent 37: 266-274.

14. Edelstein BL, Ng MW (2015) Chronic Disease Management Strategies of Early Childhood Caries: Support from the Medical and Dental Literature. Pediatr Dent 37: 281-287.

15. Wagner $Y$, Heinrich-Weltzien $R$ (2017) Evaluation of a regional German interdisciplinary oral health programme for children from birth to 5 years of age. Clin Oral Investig 21: 225-235.

16. Splieth $\mathrm{CH}$, Steffen $\mathrm{H}$, Welk A, Schwahn C (2005) Responder and non-responder analysis for a caries prevention program. Caries Res 39: 269-272.
17. Marmot M, Goldblatt P, Allen J, Boyce T, McNeish D, et al. (2010) Fair Society, Healthy Lives The Marmot Review.

18. Fejerskov O, Nyvad B, Kidd E (2015) Dental caries: The disease and its clinical management. $3^{\text {rd }}$ Edition, John Wiley \& Sons.

19. Badri P, Saltaji H, Flores-Mir C, Amin M (2014) Factors affecting children's adherence to regular dental attendance: a systematic review. J Am Dent Assoc 145: 817-828.

20. Socialstyrelsen (2013) Social differences in dental health among children and young people. Support report to The health, care and care of children and young people 2013.

21. Sheiham A, Watt RG (2000) The common risk factor approach: a rational basis for promoting oral health. Community Dent Oral Epidemiol 28: 399-406.

22. Wagner $Y$, Heinrich-Weltzien $R$ (2016) Evaluation of an interdisciplinary preventive programme for early childhood caries: findings of a regional German birth cohort study. Clin Oral Investig 20: 1943-1952.

23. Winter J, Bartsch B, Schutz C, Jablonski-Momeni A, Pieper K (2019) Implementation and evaluation of an interdisciplinary preventive program to prevent early childhood caries. Clin Oral Investig 23: 187-197.

24. Grindefjord M, Dahllof G, Nilsson B, Modeer T (1996) Stepwise prediction of dental caries in children up to 35 years of age. Caries Res 30: 256-266.

25. Schwendicke F, Dorfer CE, Schlattmann P, Page LF, Thomson WM, et al. (2015) Socioeconomic inequality and caries: a systematic review and meta-analysis. J Dent Res 94: 10-18.

26. Hoeft KS, Barker JC, Shiboski S, Pantoja-Guzman E, Hiatt RA (2016) Effectiveness evaluation of Contra Caries Oral Health Education Program for improving Spanish-speaking parents' preventive oral health knowledge and behaviors for their young children. Community Dent Oral Epidemiol 44: 564-576.

27. Colvara BC, Faustino-Silva DD, Meyer E, Hugo FN, Hilgert JB, et al. (2018) Motivational Interviewing in Preventing Early Childhood Caries in Primary Healthcare: A Community-based Randomized Cluster Trial. J Pediatr 201: 190-195.

28. Batliner TS, Tiwari T, Henderson WG, Wilson AR, Gregorich SE, et al, (2018) Randomized Trial of Motivational Interviewing to Prevent Early Childhood Caries in American Indian Children. JDR Clin Trans Res 3: 366-375.

29. Henshaw MM, Borrelli B, Gregorich SE, Heaton B, Tooley EM, et al, (2018) Randomized Trial of Motivational Interviewing to Prevent Early Childhood Caries in Public Housing. JDR Clin Trans Res 3: 353365.

30. Collett BR, Huebner CE, Seminario AL, Wallace E, Gray KE, et al. (2016) Observed child and parent toothbrushing behaviors and child oral health. Int J Paediatr Dent 26: 184-192.

31. Henry JA, Muthu MS, Swaminathan K, Kirubakaran R (2017) Do Oral Health Educational Programmes for Expectant Mothers Prevent Early Childhood Caries?-Systematic Review. Oral Health Prev Dent 15: 215-221.

32. Jiang EM, Lo ECM, Chu CH, Wong MCM (2014) Prevention of early childhood caries (ECC) through parental toothbrushing training and fluoride varnish application: a 24-month randomized controlled trial. J Dent 42: 1543-1550. 